\title{
High-Reliability Organizing (HRO) in the COVID-19 Liminal Zone: Characteristics of Workers and Local Leaders
}

Daved van Stralen, MD, FAAP, Thomas A. Mercer, RAdm, USN

\begin{abstract}
HRO has become better studied, producing concepts that bring clarity to its structure and function. Reliability, safety, and resilience, as concepts, do not carry the same immediacy of a fellow worker in danger or bringing a novice into the workforce in a way that that novice may save you. Reviewing how workers did their jobs while ensuring their own safety reveals elements of HRO that are at risk of becoming lost. We reviewed the experiences of WWII heavy bomber crews, high-rise ironworkers, underground miners, prison chaplains, fire rescue ambulance crews, and Vietnam aerial combat aviators. From their experience, we describe a VUCA-2T environment (Volatility, Uncertainty, Complexity. Ambiguity-Threat, Time Compression). Workers pass through, if not caught up in, a liminal zone. The common themes across work domains include suppressing fear, trust, helping the novice, protecting your partner, recognizing fear in fellow workers, and local leadership. Perhaps the organization's response to liminality differentiates management by high reliability organizing from conventional organization management.
\end{abstract}

\section{"Too much difference from what the} physician knows, too much discrepancy from what is expected, a disrupted response to treatment, or any abrupt change, and the neonatologist must figure something out. That figuring forms the basis of High-Reliability Organizing."

\section{Introduction}

Arriving at a resuscitation, the neonatologist looks for the familiar and what is different. Drawing upon knowledge and experience, the physician begins treating the neonate. Too much difference from what the physician knows, too much discrepancy from what is expected, a disrupted response to treatment, or any abrupt change, and the neonatologist must figure something out. That figuring forms the basis of High-Reliability Organizing.

This figuring out seems more reliable coming from scientific evidence using the best practices identified by experts. Concepts, categories, standards, and rules create norms for decisions and action (1), comforting us that we are doing the right thing. That is until an abrupt change jumps us into a different situation. Or the novelty or uncertainty of the situation keeps us from clearly identifying a specific treatment. Inability to control events or the people around us brings frustration. Failed response to treatment brings death perilously near. The drive to act rapidly becomes disorienting. The individual impulsively takes any option that appears better (2). From within the situation, all decisions are rational, and all actions are reasonable. On the outside, things look different.

Stress responses reduce distraction to create focused attention and allow our learned responses - the "tried but true." Fear reactions keep us a safe distance from the threat to create a comfortable area to work. Threat reflexes initiate action to create engagement before we can fully recognize the danger $(3,4)$. On the other hand, unmodulated stress responses inhibit memory retrieval and constrain thinking. Unmodulated fear reactions misdirect our behaviors toward offensive and defensive protective actions. Unmodulated threat reflexes focus on self-protection, paradoxically increasing failure (4).

\section{"The HRO, on the other hand, investigates failure as a result of impaired stress capacity, fear management, of threat disruptions. The HRO re-evaluates leadership and systemic decision migration, early engagement, and support to the individual operating within the} trajectory."

Unmodulated behaviors experienced as organized suites and structured ensembles become expected, even normal. We perceive them as cultural traits. Unrecognized unmodulated behaviors too easily escalate toward cascading failure (3). Failure appeared inevitable. Failure explained by events or "the system." Failure ascribed to human error or shortcoming (5). The HRO, on the other hand, investigates failure as a result of impaired stress capacity, fear management, of threat disruptions. The HRO reevaluates leadership and systemic decision migration, early engagement, and support to the individual operating within the trajectory.

A concern for leaders in an $\mathrm{HRO}$ is an undue emphasis on the normative stance at the expense of the pragmatic stance $(6,7)$. This emphasis impairs the "organizing" component of HRO and can remain covert in an untested system. HRO, conventional organization management, and all manner of reliability, safety, and resilience programs perform well in stable environments. What differ-

NEONATOLOGY TODAY is interested in publishing manuscripts from Neonatologists, Fellows, NNPs and those involved in caring for neonates on case studies, research results, hospital news, meeting announcements, and other pertinent topics.

Please submit your manuscript to: LomaLindaPublishingCompany@gmail.com 
entiates HRO from other programs is its origins within dangerous contexts, the capability to modulate abrupt disruptions, horizontal translation between industries, vertical translation within an organization, and, most significantly, the ability to extend an organization into uncertain or treacherous environments.

We can learn from industries operating in dangerous environments, but not through studies conducted in a controlled laboratory $(8,9)$. Laboratory research constrains the subject's ability to respond, which does not represent the real-world environment. Neither can a researcher mimic a live-or-die circumstance (8). Field research incorporates the heterogeneity of populations and practices, group expertise, and the spaces and concepts created by science (10). Field experience identifies gaps between theory and practice (11), the effect of granular, local influences, manifestations of stress and fear, and the local effects of threats (6).

Concepts and linear inference (scientific logic) generate the ability to predict. To predict is to prepare, thus creating a safe margin for organizational managers. To know the concept is to know the properties, thus creating a knowledge system. But predictions for stochastic environments or human behaviors, whether individual or collective, misleads planners at a fixed reference point and participants within the flux of events. Prediction for HROs is literally a matter of life or death; inaccurate models can kill (9).

\section{"To predict is to prepare, thus creating a safe margin for organizational managers. To know the concept is to know the properties, thus creating a knowledge system. But predictions for stochastic environments or human behaviors, whether individual or collective, misleads planners at a fixed reference point and participants within the flux of events."}

This article introduces into the HRO literature academic research that objectively described the field environment and presented the experience of individuals. We evaluated for consequential influence from concepts $(1,12,13)$. Mental and emotional balance, trust, and neuromodulation are learned skills. They can be readily learned within the milieu of operations.

We describe the environment that necessitates neuromodulation of stress, fear, and threat; $\mathrm{HRO}$ as a quality that emerged from adaptive beliefs and behaviors; and social cognition and prosocial behaviors as HRO characteristics.

\section{The Environment}

We can readily understand the function of stress, fear, and threat behaviors within the context of danger, yet we more commonly experience the behaviors in a liminal zone. The military concept of "VUCA" to describe threats to national security $(14,15)$ and the anthropological experience of liminality as a transition (16) have entered the lexicon of business, public safety, and healthcare. The incomplete translation of VUCA, liminality, and HRO theory into the practice of reliability and safety comes with the loss of nuance and missed, subtle cues within the environment (6). Unrecognized is the loss of neuromodulation as a skill and methods for its ac- quisition.

VUCA: Volatile, Uncertain, Complex, Ambiguous

In 1995, US Army researchers working in the Carlisle (Pennsylvania) Barracks, US Army War College, described the global environment developed at the end of the Cold War as VUCA: volatile, uncertain, complex, and ambiguous $(14,15)$.

- Volatility comes from the rapid and abrupt change in events.

- Uncertainty describes the lack of precise knowledge about the situation, our need to obtain more information, the unavailability of the necessary information.

- Complexity refers to the large number of interconnected and changing parts that come together to create the situation.

- Ambiguity describes how multiple interpretations, causes, or outcomes may be possible for one situation.

\section{VUCA-2T: VUCA with Threat and Time Compression}

VUCA is a military concept. Military professionals carry the implicit assumption that they work in a dangerous and lethal environment of "going in harm's way" (per John Paul Jones). Consequently, the concept of threat is not translated into civilian applications (17). On the other hand, the author (DvS) had included time compression into the element of volatility as the quality of instability (17, 18). A special group in SOCOM (Special Operations Command) used "VUCAT" but found the element of time compression to have such importance it should stand alone (Sean McKay, personal communication). We now use VUCA-2T though the group uses VUCA-T² (19).

- Threat impairs cognition and decision-making.

- Time compression describes the limitations on acquiring information, deciding, or acting before consequential changes in circumstances. Time compression is not a quality of time-dependence or time-limitation.

A threat more often takes place out of sight of the public. People then reject or misunderstand how threat formed HRO and how it makes a program stronger. Threat acts as a motivating condition to generate a set of beliefs and behaviors from within the ranks of workers and relatively independent of the organization or regulatory agencies (20). This form of informal subculture is an adaptation to operate in a hazardous environment. Without discussion of threat, we lose many HRO elements and misunderstand HRO characteristics.

We incorporated well-understood experiences for threats, such as military operations and high-rise ironwork, and some that people may not be fully aware of the threats such as underground mining, prison chaplain, and fire department rescue ambulance work.

Underground mining is dangerous and geographically, physically, and socially isolated. Mines operate in unpopulated, rural areas away from major population centers, emergency rescue teams, and medical care. Mining in some areas has a social and occupational stigma attached to isolation manifested in defensive group solidarity. Miners work underground in small groups, physically separated from, and unable to communicate with, other workgroups. "For the miner, danger requires a response. It is a common, day-to-day, potentially lethal occurrence" (20) 
A prison is built on the tendency of inmates to harm others. However, prisons must allow inmates to practice their own religion, including access to a religious or spiritual advisor. Prison chaplains work in this dangerous context to meet the pastoral needs of inmates. However, they must maintain vigilance for their own safety as inmates, even the inmate they counsel, may intend harm to the chaplain. Prison chaplains work as treatment staff within a correctional facility, occupying a liminal social space between corrections officers and inmates (21). This also creates an HRO-type of subculture.

\section{"It is a bit discomfiting when we find ourselves in a space we do not belong, or that is meant for passage. The discomfort arises from the loss of context but also when the discomfort triggers the sympathetic nervous system."}

\section{Liminality}

It is a bit discomfiting when we find ourselves in a space we do not belong, or that is meant for passage. The discomfort arises from the loss of context but also when the discomfort triggers the sympathetic nervous system. The triggered behaviors for stress, fear, and threat do not belong in the absence of danger, yet the trigger continues to incite these internal responses. The liminal zone described in anthropology is that space between a world we know and a world we do not, where our old rules do not apply, and we have not learned the new rules (16). In this area of experience, we must engage the situation to leave, yet we do not know what works (1).

The liminal zone challenges us as individuals but also for planning, leadership, and organizational science. These are temporary spaces where we either do not belong or that were created to pass through. We do not have context. We cannot rely on learned concepts, policies, or rules (1). We may have entered a liminal space as a neonatologist approaching an active resuscitation, or we may have space thrust upon us when a neonate abruptly deteriorates. Liminal zones also expose us to other, quite different, experiences such as a physically hostile parent or a NICU damaged from an earthquake or hurricane.

Liminal zones are not continuous with routine operations or with each other. Abrupt changes disrupt operations. Our treatments may abruptly disrupt the disease process and the neonate's physiology. Such a sequence of experiences creates the more common "punctuated experience" of resuscitation that necessitates constant evaluation and re-evaluation rather than sensemaking guiding us from the immediate past to the immediate future. "HRO is a trajectory of engagement that fuses now with the experience of then into simultaneous inquiry and redescription," Karl Weick (personal communication). Karl Weick describes the repeated presentation of abrupt changes as "punctuated sensemaking" (personal communication). Every action is a failure, and every action creates an unrelated or disconnected experience.

We would rely on our knowledge and experience, except we do not know what will work or what results we can reach. This is the "practice of reliability" to engage an uncertain problem within the liminal zone (1). Through engagement, we work to increase our chance of success while also decreasing the effect of failure. We simultaneously react to events while preventing events. This practice of reliability is an extension of our team into the liminal space at a local level and the extension of the art and science of neonatology at a larger level of analysis. This is how neonatologists and neonatology have gained life.

While this may describe common experiences, it does not describe how VUCA-2T or the liminal zone places demands on the brain's survival system. Nor how those demands affect our thinking and behavior. It is your brain that tells you that your brain is working well. Healthcare professionals in emergency and critical care believe what their brain tells them. They believe they have healthy stress, fear, and threat response for disagreements, abrupt disruptions, and danger. Thus, unmodulated cognitive functions remain unrecognized and even appear logical. "I had to yell/stare/intimidate to make the team act." Maladaptive and dangerous stress-fear-threat reactions then enter the culture and become accepted, even though lethal.

The liminal experience shapes the HRO by shaping the individual. Experience describes the changes within an individual due to the environment (1). The liminal zone's more severe environment has a profound effect on the individual, sometimes as a larger number of small liminal experiences or fewer but more severe incidents. What makes High-Reliability Organizing is not the number or severity of liminal experiences but learning how to perform in the liminal zone. These are lessons learned firsthand for prison chaplains rather than by instruction, such as an inmate who uses trust to manipulate the chaplain. Liminal experiences have three functions for chaplains (21):

- a rite of passage for chaplains that proves their mettle and demonstrates an ability to navigate these situations;

- $\quad$ teaching to be proactive for assessing potential problems with inmates and engage early rather than allowing them to escalate;

- $\quad$ providing up-to-date "lesson stories" to be shared.

Engagement of a liminal experience, rather than passive endurance, change the cognitive domain and the affective domain. Perhaps the differentiation of trust, risk, and danger between pragmatic and normative stances (6) lies in the lexicon of liminality.

WWII American bomber crews arriving in the theater of operations were insecure and defensive. In action, they were overly selfassured though some were particularly diffident (22). About their tenth raid [the airmen had entered and remained in liminality]:

the man had experienced fear and by now knew that he could deal with it; he found that care and skill and coolness in the pilot and crew had a real bearing upon the question of his return; he saw that his crew and his airplane could withstand catastrophe; he developed an "esprit de corps" regarding his squadron, and was now really part of it. He developed for the first time a sense of his responsibility to his mates and to formation. At this stage... the men were effective, careful, fighting men, quiet and cool on the ground and in the air. They attained a sort of tranquility despite their anxiety. They had very little need for defensive mechanisms of any sort to deceive themselves or anyone else. [Authors' emphasis.] They talked easily and quietly (22).

\section{Neuromodulation of stress, fear, and threat}

Drive the course as fast as you can in the police car. Two runs. Then we learn if we passed the LAPD "skid school" for high-speed 
driving. For the second run, we used the siren. All of us, fire department rescue ambulance drivers, had passed. We asked what the failing time would be. "There isn't one. If you drove faster with the siren, that means you are run by adrenaline. We don't want you" (DvS, personal experience).

\section{Manage your fear}

A second-year pediatric resident felt her mind freeze. As the critical care transport physician, she walked up to the head of an infant in cardiac arrest. The referring team left when they saw her enter the emergency department. They had been unable to achieve a sustainable heart rhythm. Her mind froze; she couldn't think. That is the report she gave one of the authors (DvS) when she returned to the PICU. She said it was a familiar sensation as the author had earlier given her an exercise to recite the months of the year alphabetically. The exercise demonstrates how quickly cortisol impairs memory retrieval. Inability to think in a crisis is a neurochemical effect, not a measure of cognitive ability or intellect. She checked the endotracheal tube "because it was working." She could immediately think and then stabilized the infant in 20 minutes. Voluntary, directed movement can counter cortisolmediated freeze.

One paradox of fear is managing fear through the act of not showing fear. This is not the same as not showing fear through denial of the threat or false bravado. This comes from the acceptance of fear by all participants with the realization that showing fear impairs performance (personal experience and observation of the authors; $(21,23,24)$. A major norm in mining is to not become victim to your own emotions, "don't get excited," "play it cool" (23). Described by a journeyman high-rise ironworker, "One must accept danger and fear without allowing it to control or adversely affect your behavior" (24). For the prison chaplain, one state code of ethics includes, "I will be constantly mindful. To the best of my ability, I will remain calm in the face of danger" (21).

Those with personal experience have learned that suppression of the fear response reduces the effects of fear. They each learn methods to neuromodulate during their routine dangerous tasks. Experienced veterans also learn how the expression of fear alone spreads the fear response to others. In mining, one can express frustration through an emotional outburst, but there is a limit that the outburst must not pass (23). For the prison chaplain, recognizing the threat from being alone in a prison yard enhances alertness, yet they also recognize sustained levels of alertness negatively affect thinking, generate paranoia, and create cynicism and skepticism for people's intentions (21).

\section{"One paradox of fear is managing fear through the act of not showing fear. This is not the same as not showing fear through denial of the threat or false bravado."}

\section{One piece of information}

The engine stopped. He was flying a small Pacer airplane up the mountains toward a pass in an area with a big valley surrounded by mountains. Going up the mountain when the engine went out. The only way to land was going up the hill. He thought about what to do. He figured he could dive downward. Then, while he still had flying speed, he would turn up to land uphill toward the end of the valley.

On another flight, he was flying at night when the engine stopped. It was out of gas; he had no gauges, had no instruments, and had no lights. He began a descent into a forest, planning for the trees to break the landing. One hundred feet above the trees, quickly coming into view, he saw a field. He lowered the landing gear to slow his airspeed and went for the field. The landing gear, not fully deployed, caused the plane to swerve as it crashed.

The $3 G$ force was what kept him thinking. In a small plane, he had been told the cockpit could handle a landing with a force of $3 \mathrm{Gs}$. Knowing he would be safe no matter what happened, he was able to figure out a solution.

Both crashes occurred in the early 1950s. In 2018, he learned how a person could neuromodulate thinking when in danger. That is when he understood how he could think clearly while his plane was about to crash into a mountain pass or into trees at night. One piece of information, safety at $3 \mathrm{Gs}$, was enough for him to think clearly.

Charles Aldridge, personal communication to the author (DvS).

You are part of your equipment. Feelings are powerful and influence thinking, behavior, and body functions. That was the message given to airmen in preparation for the emotional stresses of combat in WWII (25). While anger and fear emerge in many forms, what counts is its direction toward destructive or constructive effects. "Fear must be clearly related to its real cause, and that relationship must be maintained, because you can't attack a problem if you don't know what the problem is, "David G. Wright, Captain, Medical Corps, USAAF (25).

\section{A subculture for dangerous contexts}

"The requirement for reciprocity applies to most social exchanges and is especially pronounced during occasions of danger or accidents. Miners know that they can count on other miners to be available and lend assistance during their moments of peril. They also know they are expected to and will return a similar favor to another miner someday in the future" (23).

HRO was codified from the Nimitz class nuclear aircraft carriers. The system called HRO emerged from 1) the experience of 35 years of naval aviation warfare, 2) Captains with both aerial combat and complex ship handling experience and nuclear propulsion training, and 3) the high technical knowledge and professionalism of the nuclear-trained crew (7). What is easily missed is how HRO developed from routine operations in the liminal zone.

The liminal zone more than distinguishes HRO from other approaches for safety, reliability, and resilience. Liminality also distinguishes operational organizing from administrative organizing, leadership at the operational level from executive leadership, and operations within the trajectory of events from observation and operations at a fixed point. Most significant, liminality underscores the necessity to have neuromodulation of stress, fear, and threat integrated into the organization.

Entering a VUCA-2T environment or a liminal zone, we shift our orientation from routine work to short-term objectives. From a distance, it appears to make sense to have training and plans in place. The expert following the rules performs poorly $(26,27)$ and has plans for everything to have plans for nothing. The HRO organizes differently because, despite best intentions, "What you do in an emergency is what you do every day," Jim Denney, EMS 
Captain, LAFD, US Navy Seabee Vietnam Veteran. This article introduces methods for individuals and small groups to develop daily operations that rapidly expand for emergencies.

\section{"The liminal zone more than distinguishes HRO from other approaches for safety, reliability, and resilience. Liminality also distinguishes operational organizing from administrative organizing, leadership at the operational level from executive leadership, and operations within the trajectory of events from observation and operations at a fixed point."}

To "manage your fear" refers to the affective response, not to disregard the threat. Experienced workers accept the threat's reality, which means they teach the novice how to work around the threat.

From daily to emergency

Accurate observation and description will reframe the situation from imagination to actionable concreteness. The prison chaplains' experience being observant reduced their stress working in prisons and aided their vigilance for things "not right." As a result, they experienced less complacency, a well-known danger in prison work (21).

Along with accuracy in observation is accuracy with the lexicon. A primary step Ron Stewart (founding president of the National Association of EMS Physicians) took when creating the paramedic program in Los Angeles County was accurate medical terminology and descriptions (personal observation, DvS). Manifestations of this step influenced information gathered in the field, communication with physicians and hospital personnel, and medical thought processes. The author continued this method by creating a PICU, critical care transport program, and subacute care programs. The prison chaplains changed negative words, like "riot," to neutralize the lingering feelings of negative feeling. They could remain cautious without becoming overwhelmingly paranoid or too fearful to work (21).

A final comment on accurate observations and how they influence our thinking, adrenaline does not cross the blood-brain barrier. There is no adrenaline in brain tissue because adrenaline does not cross the blood-brain barrier (26).

\section{Human safety systems}

The human stress system evolved to support an effective response against an acute physical life threat, assisting immediate escape and survival (27-29). Neuromodulation of this rescue system, part of the sympathetic nervous system, allows harmony with the growth system, or parasympathetic nervous system, for adaptation to various circumstances.

Neuromodulation allows the stress-fear-threat system to balance our human response to the level of demand. In this way, we reduce our reactions when called for resuscitation and find the neonate responded to initial treatment, and we accelerate our reac- tions when the neonate we are treating deteriorates abruptly.

Without neuromodulation, the stress-fear-threat system contributes to unrecognized, normalized, instrumental, and even institutionalized maladaptive behaviors. These behaviors come in suites of related behaviors common to humans and ensembles of behaviors developed within individuals from instrumental experience (3). A shared threat, such as fear of malpractice, error, or a leadership style, creates the ecology of fear, further normalizing maladaptive behaviors that contribute to a culture of fear. The strength of the stress-fear-threat system is lost.

Stress, fear, and threat motivate engagement, maintain a safe working distance, and focus attention toward action $(3,4)$. Military and public safety operations rely on the neuromodulation of stress responses, fear reactions, and threat reflexes.

One author (DvS) has educated staff for neuromodulation during the development of a PICU, subacute care facilities, and several EMS education programs. However, the wrong education substance (teaching and content) makes good people and organizations vulnerable to compensated but covert failure. They will not recognize or identify the proximity of failure because the system continues to operate. Operations will continue through failure until there is an abrupt, severe disruption with unexpected catastrophic failure.

\section{HRO emerging from adaptive beliefs and behaviors}

This material comes from observations written within a dangerous context before extramural regulations circumscribed behaviors or concepts became established that would influence interpretation. This is the material experienced veterans shared with novices.

\section{"Without neuromodulation, the stress- fear-threat system contributes to unrecognized, normalized, instrumental, and even institutionalized maladaptive behaviors."}

It seems intuitive, if not prudent, to select personalities for highrisk work. At the least, we would want training designed for work in confusing environments with rapid, abrupt change. These industries - WWII heavy bombing, US Marine Corps recruit training, high-rise ironwork, hard rock mining, prison chaplain - trained the novice to the job and allowed the intensity of danger to reinforce what was learned. One psychiatrist joined a B-17 crew "to a distant target in enemy-occupied Europe." He observed a crew of diverse personality types in action, everyone wounded, the plane badly damaged and flying alone, with successful return to England in doubt (22):
"It was striking that the emergency did not tend to in- crease the differences in the reaction patterns of the dif- fering personalities; rather they came to act in much more similar fashion than usual...The reduction of all personal- ity types to a common reaction pattern appears to be a matter deserving contemplation."

A second difficulty arises when incorporating bona fide experience into any safety, reliability, or resilience model: the inability to compare liminal experience and engagement to established 
laboratory or field studies. The academician seeks to generalize research findings across many settings, seemingly unidirectional from laboratory settings and peacetime to operational, live-or-die, in extremis situations (30). Observers outside the liminal experience or who use a fixed frame of reference (6) rely on a deduction to categories using linear inference to place new information into known concepts (1).

\section{"It seems intuitive, if not prudent, to select personalities for high-risk work. At the least, we would want training designed for work in confusing environments with rapid, abrupt change."}

While translating between these environments seems counterintuitive, we argue in this paper that migration of the model to one of the human-circumstance interactions will illuminate the similarities and elucidate the mechanisms. There is a gap between observations in combat and laboratory studies(30), theory and practice (11), discrete concepts and continuous perceptions (31), and

abstractions and concreteness (Karl Weick, personal communication). Engagement in the liminal zone melds both sides of the gap (6) to bring an understanding of $\mathrm{HRO}$ to those outside live-or-die experience.

\section{Functional nature of the subculture}

The subculture that develops for hazardous work - the rules, beliefs, attitudes, and values - reduces the expected mental stress. As a subculture isolated from the general population, those who work in dangerous contexts constrain each other to safety norms (20).

Ironworkers will "binge" each other, harassment meant to reinforce boundaries and mental control of emotions (32). Miners constantly assumed that how a miner worked could avoid accidents and that recognizing and coping with potentially dangerous situations could be learned. They always respected a dangerous situation. They did not bend or ignore rules (20). Clergy build their culture with trust, yet clergy working in prisons, prison chaplains, learn to "watch out" when they work in prisons. They must apply their pastoral skills in an institution not built on trust, where the worst can happen, with inmates having tendencies to harm others (21).

\section{Leadership}

Organization management reaches its limits at the ambiguous, moving boundaries of liminal zones and deadly contexts $(6,30$, 33). The May 1996 Mount Everest climbing disaster illustrates the unrecognized risk inexperienced people generate when they knowingly cross the liminal zone threshold or enter a dangerous

Readers can also follow

NEONATOLOGY

via our Twitter Feed

@NEO context $(33,34)$. We are well-served to remember the chemistry lab mantra - "hot glass looks like cold glass." A dangerous mountain looks like a safe mountain. A miseducated organization looks like an HRO.

Leadership for high altitude mountain climbing developed from experienced participants. As climbing became settled, novices and outsiders began high altitude climbing. May 1998, a low-pressure weather system passed over Mount Everest. This was the equivalent of abruptly gaining several thousand feet, a deadly occurrence at that altitude for the climbers. The environment looked the same. The threat was not visible to inexperienced sojourners on the climb and was disregarded by some experienced leaders (33). Eight climbers died.

What works in a stable, predictable environment also works in the liminal zone and dangerous contexts. However, the longer it works, the stronger the belief that outsiders and inexperienced leaders have in their leadership and management abilities. What becomes lost is the unique knowledge and experience necessary for liminal zones, dangerous contexts, abrupt changes, and punctuated events. Designs and the normative stance work...until they don't. In the subsequent chaos, "if you don't have it, it doesn't exist" (a common firefighter sentiment).

Operators engage within the turbulence and trajectory of events, generating information and knowledge for lessons learned (1, $6)$. A fixed-point reference frame outside the flux of events has a broader view with less confusing nuance. Concepts neatly and rapidly coalesce, partly for the purposes of organization management and sometimes for the needs of distant regulators and customers. The speed, putative strength, and familiarity of these accounts drive them to dominance. Lost are the experienced hidden voices that captured ephemeral lessons learned (34). As the baseline shifts (35), the subculture for dangerous contexts drifts, looking more and more like the dominant culture.

\section{"The May 1996 Mount Everest climbing disaster illustrates the unrecognized risk inexperienced people generate when they knowingly cross the liminal zone threshold or enter a dangerous context $(33,34), "$}

Leadership in dangerous contexts and the liminal zone is local, an ephemeral nature rapidly shifting between those with local information and those with knowledge for action (personal observation of the authors; (36)). This type of leadership supports selforganization during the event and the necessary improvisation to generate solutions (18). It naturally arises during the experience of lethal threat (interviews by the authors; (36)).

In mining, the shift boss worries that the inexperienced miner will most likely be injured. For novices, accidents were due to ignorance. Miners have a uniform belief that guidance and experience make a good and safe miner. It is the shift boss's responsibility and experienced miners to teach and mentor new workers (23).

The United States Marine Corps uses social learning theory (37) during recruit training for socialization and to model desired behaviors. The drill instructor facilitates this enculturation $(38,39)$.

Fear is not weakness 
Fear is taken for granted. You can have fear yet continue to work and be accepted by your colleagues. There are no cowards. Withdrawing from a dangerous situation does not diminish one's reputation in mining (23) or ironwork (24). Miners and ironworkers respect others' fears and limitations without testing their courage $(23,24)$.

Military and public safety operators also accept an individual's fear, yet they must follow through to engage the problem despite an elevated probability of death [personal experience of the authors; interviews with San Bernardino City Police officers and Bouches du Rhone (France) fire officers; (38)).

Fear is the only natural reaction to the inescapable threats of combat. It is common to everyone.

"Leadership in dangerous contexts and the liminal zone is local, an ephemeral nature rapidly shifting between those with local information and those with knowledge for action (personal observation of the authors; (36)). This type of leadership supports self-organization during the event and the necessary improvisation to generate solutions (18)."

"The whole physiologic reaction of your body to fear is to prepare your body for action. You are prepared to respond to threat with vigorous action. When you cannot respond, you still have the sensations necessary for response" (25). That is the quandary of fear and anger, your body has prepared you to respond. But you cannot.

\section{Help the new member}

Uncontrolled fear responses impair performance not only in dangerous situations but also can create a dangerous situation. Both novice and newly hired veterans are at risk. The novice is gaining experience in a new discipline while the newly hired is learning a new team. Both individuals operate in a liminal zone.

Not possessing the requisite knowledge and skill results in poor performance and injury. The focus on training and the apprentice period is to develop qualified members. Miners believed it is the duty of the veteran miner to guide and teach the novice miner. The new miner would learn to work in a way to avoid accidents, recognize potential danger, and learn how to respond to such situations (23). Journeyman ironworkers told apprentices how to act by having them think out their tasks and make sure their coworkers do the same. The journeyman would present situations, even if it was not the job of the apprentice. The apprentice would then give interpretations of the proper actions as "part of the process of sharing this perspective about fear and threatening coworkers" (24). The US Marine Corps sees recruit training as developmental and positive despite the high personal demands. Drill Instructors were are present to help, not harass the recruit (38-40).

In ironwork, apprentices cannot appear incompetent because they can inadvertently cause serious problems. Asking questions can be a sign of incompetence, just as not asking questions could be. The apprentice ironworker dilemma is the dilemma of a novice nurse, resident, or attending physician in the NICU - how to learn without revealing ignorance (32).

Prison chaplains are taught that awareness can help control risks and prevent problems. Abrupt social disruptions erupt from resentments nurtured over long periods. Alert officers and veteran chaplains notice the subtle warning signs. The vigilance of prison chaplains for subtle changes in human behavior is much the same as an experienced leader in an HRO - "anticipate risk in order to control it effectively," and "chaplains assumed the existence of risk, even in the absence of evidence of a clear threat" (21).

There was no effort in these dangerous industries to scare or test the novice's mettle with situations or horrible stories of death (23, $24,38)$. Rather, veterans were supportive. In the mines, a new miner would be greeted with comments along the lines of: "First time in a mine? Don't worry; it ain't that bad. You'll do all right" (23). The experienced veteran gives meaning to the feeling of fear and stress.

Every state and facility corrections training for prison chaplains has a strong focus on the threats from inmates, often in the first section of the training session. Training includes how to negotiate risky situations when the prison chaplain is alone, including being taken as a hostage (21).

To increase stress capacity and performance in US Marine Corps recruits, successful drill instructors in the 1970s set the tone of the social environment in training. These drill instructors, nearly all Vietnam veterans, were significantly more job-involved, held higher internal control expectations, were significantly less impatient and less prone to anger, were lower in physiological arousal, and emphasized self-control of emotions. They also had more realistic job expectations and greater empathy for recruits (40). Their beliefs, expectations, and attitudes influenced the recruits' self-appraisals and expectations (41). Drill instructors with lowattrition units used reward contingencies to internalize locus of control. Even recruits who had had negative or failed experiences in life, such as failure, rejection, and emotional disruption, developed the belief that success will result from their own efforts (39, 42). Recruit training increased recruits' stress capacity by increasing training demands and from drill instructors who developed the recruits' capability for effective performance under stress conditions (43).

\section{Stress for stress}

"Just how does cortisol help you learn?!" Joe Martin, Battalion Chief, LAFD (retired), asked his training captains in the drill tower. The captains had incorporated into training activities for gratuitous stress. Some of the captains believed that a recruit learned to deal with stress by being stressed, while others believed they needed to keep the recruits from believing they are smarter than average. Martin understood that stress to the degree of cortisol release impairs learning and memory formation. Haas $(24,32)$ and Fitzpatrick $(20,23)$ described the support experienced workers gave to the novices in ironwork and mining, respectively.

This is not a rare belief. When one of the authors (DvS) observed this frequently in medical education, the individual taught this way because the military used the techniques. None of the respondents had served in the military - they said they had learned from the movies. In the 1970s, the Marine Corps did have a period when drill instructors believed the only way to produce good Marines was with high stress and a heavy-handed approach (39, 40). No scientific evidence supports the belief that intentionally 
imposed stress increases the student's capabilities. Conformity is not discipline. The Marine Corps changed its program (38).

In the HRO, stress has no utilitarian value. Stress is not used for education, training, emphasis, behavioral modification or control, or bullying. Rather, the HRO considers stress from the organization to be a systemic failure, removing the necessary freedom to act early in response to a discrepancy or disruption. Stress, fear, or threat behaviors in an individual are more serious as they have several causes. These behaviors must not be allowed to affect the behaviors of others.

\section{Stories teach and share}

In the mid-1970s, Angel Dust (phencyclidine or PCP) initially arrived in the area where one author (DvS) served on a fire rescue ambulance (RA). PCP's effects as a dissociative anesthetic caused violent behavior and hallucinations in some victims. The RA crews would call the police for "officer needs help," which resulted in a tumultuous scene, increasing the possibility of injuries and arrests. Passing along stories of what worked created a body of knowledge that, within six months, the crew of the RA could manage a PCP response without assistance. Within an HRO, stories have a privileged role in generating and diffusing knowledge.

Workers in dangerous industries use stories to teach and for socialization (17). Stories bridge the gap between the tacit and the explicit. Stories as anecdotes deliver social knowledge to maintain or change a culture. Stories carry values and tacit social knowledge, allowing knowledge to be demonstrated and learned without the need to make formal presentations of ethics or to specify in detail the proper behavior. We share lessons we have learned from unique or novel situations. Stories can impress on the novice the effects of poor decision-making skills and the need for vigilance against the early signs of a crisis.

\section{"In the HRO, stress has no utilitarian value. Stress is not used for education, training, emphasis, behavioral modification or control, or bullying. Rather, the HRO considers stress from the organization to be a systemic failure, removing the necessary freedom to act early in response to a discrepancy or disruption."}

In mining, stories commonly focus on the most common event rather than fires or cave-ins that the miner cannot prevent. Often these stories tell of the new miner floundering until an experienced miner rescues and guides the new miner. This reflects the "uniform belief that a man needed the guidance and wisdom of an experienced miner to become a good miner" (23). For example, a journeyman ironworker told some ironworker apprentices on a bridge who had his hat on backward. When a wind gust blew the hat off, he reached out to grab it, lost his balance, and fell 100 feet into the water. In one story, even if apocryphal, the journeyman instructs the apprentices of the problem of wind and rain to put their safety first, then worry about their clothing and equipment later (24).

In dangerous contexts, stories teach without the need for direct exposure to a threat. An "incident story," not to be mistaken for the "war story," gives a concrete example of a situation and its solution. Incident stories always incorporate a principle. Prison chaplains learn about their surroundings, inmate behavior, specific troubles, precautions, and solutions from incident stories. More general stories provide lessons for general threats, acting more like cautionary tales that apply to everyone (21).

Rather than teaching thinking and performance, some people use stories to describe prohibitions and warnings. These stories tell the novice what to do or not do rather than how to perform. This difference, prohibition versus performance, is nuanced but relevant to the HRO. A "cautionary tale" stops curiosity, associated with a strong will, masquerading as an educational tale to control behavior. Such stories create a "pedagogy of fear" (44) that contributes to the ecology of fear (45) found in many organizations and industries.

"Stories bridge the gap between the tacit and the explicit. Stories as anecdotes deliver social knowledge to maintain or change a culture. Stories carry values and tacit social knowledge, allowing knowledge to be demonstrated and learned without the need to make formal presentations of ethics or to specify in detail the proper behavior."

Stories also have a neurological function. Novices tend to tell stories to process their immediate personal experiences. Experienced veterans often integrate both inner and outer realities, which produces understanding and is a central component of wisdom (46). Narratives are well-crafted anecdotes that describe the experience and the underlying principle. Such stories are ordered sequentially yet understood as a whole. Narratives require various structures in the brain, including conscious memory, knowledge, sensations, feelings, and behaviors. In this way, narratives integrate neural systems in the brain and socialize us into a culture (46).

The experienced veteran helps interpret the novice's stories and has a duty to share stories with the novice for guidance.

\section{Protect your partner}

"Look out for the other man" (23). "You never do anything without first making sure that your partner's all right" (24). Amid a heated discussion between several fire officer colleagues and the author (DvS), an RCP (respiratory care practitioner) interjected, "I thought you were friends. Why are you fighting?" One officer (Joe Martin, Battalion Chief, LAFD, retired) had worked with the author on the fire department rescue ambulance in a high drug and gang area. Martin responded, "We're sparring. You don't want your partner to go out without knowing his weaknesses or making him stronger, do you?" The RCP had not thought in terms of entering a dangerous social environment alone.

Among ironworks, preventing misunderstandings during a crisis while "running the steel" requires a "sparring match of social ges- 
tures." This teaches the ironworkers how each will respond when the need to communicate freely, curtly, and, at times, forcefully occurs during a crisis (24). A threat to anyone is a threat to everyone.

"Looking after one's partner is the strongest and most immediate requirement and is adhered to even when there is conflict between partners" (20).

\section{"Stories also have a neurological function.} Novices tend to tell stories to process their immediate personal experiences. Experienced veterans often integrate both inner and outer realities, which produces understanding and is a central component of wisdom (46)."

Neonatologists are aroused by the distress of the babies, their parents, and NICU staff. Empathy is this vicarious sharing of another person's internal state. For ironworkers, empathy and their perspective of fear drive workers to watch out for each other. Ironworkers protect others from any situation that increases the common danger (24) while miners share tasks and warn others of dangerous situations (23). Workers can have strong opinions, but they come together against occupational threats. Empathy is one of five HRO values identified by the authors (dignity, honesty, humility, empathy, and duty) (17). HROs work in tough situations where people are going to fail, and it could be any of us doing the failing-"There but for the grace of God go I."

\section{Recognize fear in your partner}

The resuscitation of a child began accelerating. The author (DvS) asked a nearby nurse for assistance. The newly hired nurse peering into the room begged off to take routine vital signs in the adjacent room. The author then asked if the nurse could prepare a dopamine infusion, and he returned to the resuscitation. Within a few minutes, the nurse entered the room, set the dopamine infusion on a table, and joined the team. Acceptance of the initial response and voluntary movement modulated the nurse's affect and influenced cognition, resolving the fear response.

A major norm in mining is to respect the fears of others. It is not a sign of weakness to withdraw. You do not test a miner's masculinity or courage as there are no cowards in mining (23). During a wildland firefighting staff ride, participants discussed cutting a fire line on an extremely steep ridge. Several Hot Shot Crews declined the request. The main question for discussion centered around the crew that cut the line - did the crew have greater experience which enabled a successful cut, or did their lesser experience place them in harm's way? (Personal observation, DvS). [A staff ride is an on-site, structured study of an incident.]

We more commonly think of fear as incapacitating. While that does happen, insidious and more common is the individual who performs in a state of unrecognized fear. Miners protect the greenhorn who lacks experience and knowledge and provide on-thespot instruction (23). Ironworkers, working more independently, watch for the worker who is afraid. Such workers are unpredictable and can cause serious accidents (24).

Whether workers in dangerous contexts avoid or instruct a fearful worker, the reasons are the same: "Ignorance and lack of skill resulted in injuries" (23). A fearful worker will not act correctly, may act rashly, will put self-protection over group protection, places priority on his emotions, and neglects or avoids his responsibilities (24). The novice will flounder without the "guidance and wisdom" of experienced miners (23). Prosocial empathy increases group affinity and reduces stress responses and fear reactions through oxytocin systems (47-49).

\section{Trust}

One author (DvS), as a rookie on a fire department rescue ambulance, had called for a fire company to assist. The senior captain approached and asked what was needed. Believing his captain should decide, the author began to describe the situation. The captain cut him off and simply wanted to know what was needed. With that request, the author understood that his descriptions and requests would be accepted "as is" and acted upon. At that moment, the author understood the imperative for accurate descriptions and the gravity of every decision. The captain, William J. Corr, became his mentor, quoted in many of the author's publications.

Trust afforded colleagues is a determinant of the level of danger operators can accept (personal experience of the authors; (24, 32)). Trust in the operational domain is transactional between two people, similar to trust in the business domain. Keiretsu, a component of lean systems, describes how Toyota used trust to develop mutual benefit in partnerships to coordinate productivity and support long-term relationships with suppliers (50). Having high levels of trust is crucial for the transfer of tacit knowledge in the lean system (51). But trust in the liminal zone differs from trust in the business sense. The transactions can occur in moments and may or may not carry a moral equivalent. We trust a person to the extent of their capability. On the other hand, our trust may abruptly change as described by a US Army Combat Medic and Vietnam Veteran (personal communication), "I trust you until I see you putting yourself first." This comment distinguishes trust in the lexicon of liminal operators from that of the business community.

\section{"We more commonly think of fear as incapacitating. While that does happen, insidious and more common is the individual who performs in a state of unrecognized fear."}

Trust in prisons provides a good example of the utilitarian use of trust. The environment is constructed for distrust, and staff are taught not to trust $(21,52)$; trusting colleagues is the same as other dangerous contexts. However, continual treatment of inmates without trust creates worse problems working with inmates (52) and is counter to a prison chaplain's ministry (21). When we use trust as a tool and appreciate the myriad of reasons why people

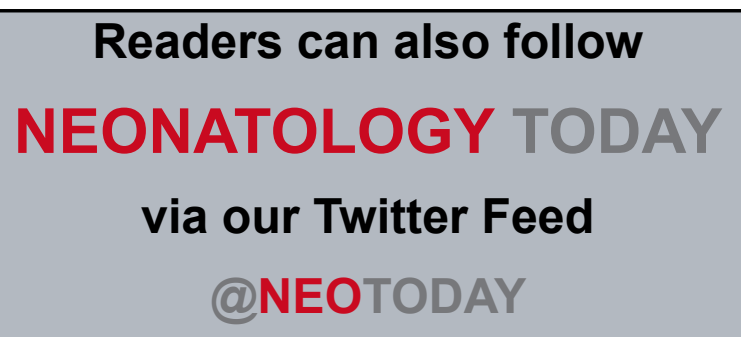
NEONATOLOGY TODAY via our Twitter Feed @NEOTODAY 
cannot be trusted, we begin to accept the firefighter's situational statement about trust, "I trust myself, so I can trust you."

Trust as consistency in performance or a character trait can be cultivated-the US. Marine Corps formally cultivates character starting with recruit training (38). Civilian organizations are unable to cultivate trust and character in the same way. Members who work in dangerous contexts may "assay" for a person's ability to perform in the liminal zone in a manner that stresses its importance, teaches how to trust, and identifies those less trustworthy.

Firefighters and ironworkers in the 1970s tested trust or harassment or "binging," respectively. One author (DvS), assigned as a rookie to a busy fire department RA, noticed the firefighters would target a new transfer for harassment. His partner explained they would see what it takes to make the new firefighter "pop his cork," that is, to become infuriated rapidly. They would then know what made the firefighter angry and what the anger looked like. During an emergency, they would leave each other alone yet maintain vigilance for triggers and early signs of anger in each other. Should either occur, the other firefighters would engage in protecting the susceptible firefighter. Ironworkers used binging to test self-control under pressure. Ironworkers who lose control during binging will likely be worse in an emergency (32).

Rather than trust as an HRO value, the authors use honesty what someone says represents the circumstances (17). Trust is a transaction that can be influenced by bias and experience.

\section{Conclusion}

The "figuring out mechanism" for VUCA-2T and the liminal zone makes the HRO. We found the elements of figuring out had developed in several domains without the formal introduction of HRO concepts. These are domains where a threat is immediate and personal: WWII heavy bomber crews, ironworkers, hard rock or underground miners, prison chaplains, fire rescue ambulance crews, and Vietnam aerial combat aviators. HRO emerged from adaptive beliefs and behaviors found in these social groups.

These domains had traits of HRO, yet they developed outside the concepts of HRO. One of the authors (TAM) had invited Karlene Roberts to study the crew of his ship, the USS Carl Vinson. Roberts described the crew's performance in the first article that coined the term "High-Reliability Organizing" (53). Roberts had submitted a research paper for publication describing the work of one of the other authors (DvS) developing a PICU (54). Roberts and Bea

described the development without the label HRO because the PICU was developed before the codification of HRO (Karlene Roberts, personal communication, DvS).

These HRO traits reflect the workers' focus to help each other get the job done while working around danger. Keeping calm during daily work ensured they were calm during an emergency. All workers learned to engage discrepancies and disruptions. They also learned to identify and engage events earlier during the covert but compensated phase of failure. At some point in their experience, early engagement becomes prevention.

The amalgamation of response and prevention for routine operations expanded with little change to form emergency operations. In every emergency, responders identify and prevent further disruption while simultaneously responding to control the emergency. This nature of HRO, at this level of analysis, facilitates the translation of $\mathrm{HRO}$ to diverse industries and throughout the hierarchy of an organization.
It can be viewed as a liminal rite of passage; the novice passes from the civilian world to a new "HRO" subculture. Experienced veterans are vital to this passage. A threatening, disorienting experience creates the feeling of vulnerability. No one wants that to happen to them again. Cognitive and affective fragmentation will resolve. Immediately after an incident, the individual becomes susceptible to dysfunctional coping mechanisms, maladaptive beliefs and behaviors, or harmful principles and concepts. In the $\mathrm{HRO}$, the experienced veteran models effective, adaptive beliefs and behaviors necessary for the job.

\section{"Trust is a transaction that can be influenced by bias and experience."}

$\mathrm{HRO}$ is leadership, and leadership sustains High-Reliability Organizing. Hidden voices within the HRO tether the dominant account. During a crisis, ephemeral leadership anchors operations by rapidly and locally addressing discrepancies and disruptions. Minimal impairment on operations continues the organization's core work, work necessary to support the emergency response. This approach, to work with stress, fear, and threat, is learned by modeling leaders' beliefs and behaviors.

Help the new member control fear responses, identify danger, and become trustworthy. You are teaching the novice to protect you, which is to "protect your partner." This form of empathy is one of the five HRO values identified by the authors. HRO empathy leads to rapid, nonjudgmental support for colleagues and facilitates learning when everyone accepts, "That could happen to me."

Stress has no utilitarian purpose in dangerous contexts. Fear, as an instructive construct, teaches the novice what to look for and how to respond. In no situation do these domains working in dangerous contexts use stress or fear to interfere with thinking and acting. Informative stories teach safety and reliability. "Pedagogy of fear" stories create an ecology of fear (45). Modulated emotions, incorporation of fear, trust, and empathy emerge from the

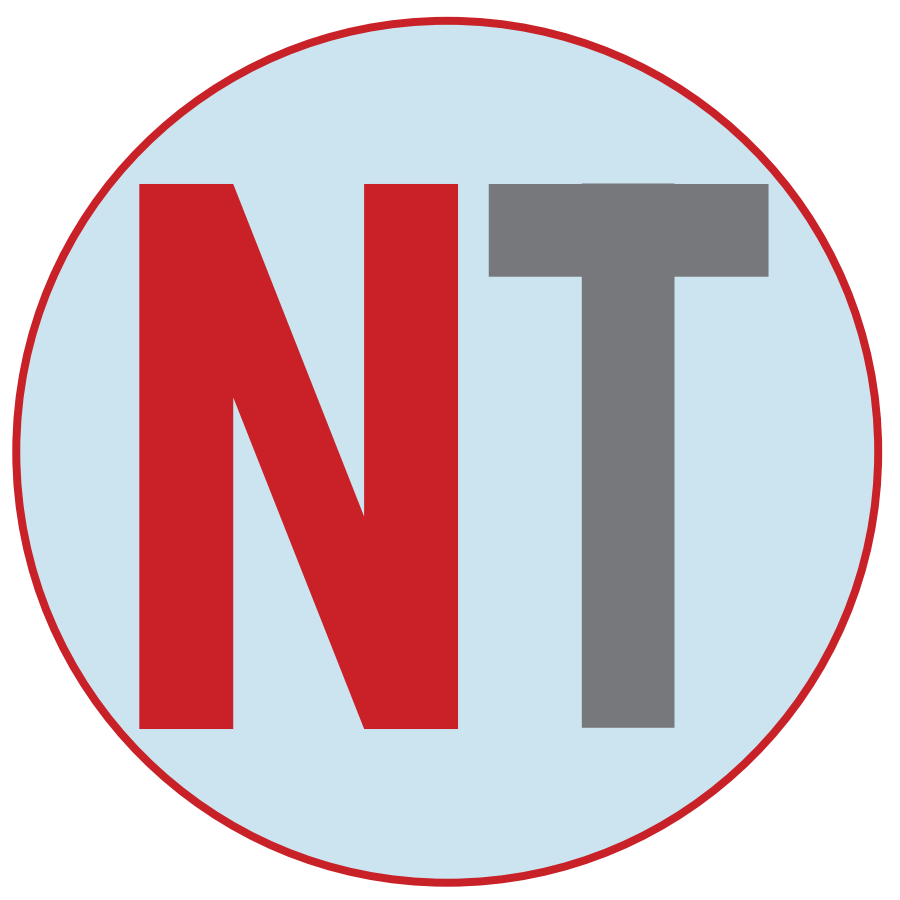


rite of passage into the liminal zone. These traits do not appear without the modeling of leaders. In an HRO, every person is a leader.

Perhaps the organization's response to liminality differentiates management by high reliability organizing from conventional organization management.

\section{References:}

1. van Stralen D, Mercer T. The Nature of Neonatal Experience during Pandemic COVID-19. Neonatology Today. 2021;16(3):87-97. doi: 10.51362/neonatology.today/202131638797.

2. Janis IL, Mann L. Decision Making: A Psychological Analysis of Conflict, Choice, and Commitment. New York, NY: Free Press; 1977.

3. van Stralen D, Mercer T. Pragmatic High-Reliability Organizations (HRO) Modulate the Functions of Stress and Fear Behaviors During Pandemic COVID-19: The Stress-FearThreat Cascade. Neonatology Today. 2020;15(10):126-34. doi: 10.51362/neonatology.today/2020101510126134.

4. van Stralen D, Mercer T. During Pandemic COVID-19, the High-Reliability Organization (HRO) Identifies Maladaptive Stress Behaviors: The Stress-Fear-Threat Cascade. Neonatology Today. 2020;15(11):113-24. doi: 10.51362/neonatology.today/2020111511113124.

5. van Stralen D, Gambino W. Error as a Faulty Failure Signal. Neonatology Today. 2020;15(9):114-7. doi: 10.51362/neonatology.today/20209159114117.

6. van Stralen D. Pragmatic High-Reliability Organization (HRO) During Pandemic COVID-19. Neonatology Today. 2020;15(4):3-9.

7. van Stralen D, McKay S, Mercer T. Flight Decks and Isolettes: High-Reliability Organizing (HRO) as Pragmatic Leadership Principles during Pandemic COVID-19. Neonatology Today. 2020;15(7):113-21. doi: 10.51362/neonatology.today/20207157113121.

8. Berkun MM, Bialek HM, Kern RP, Yag K. Experimental Studies of Psychological Stress in Man. Psychological Monographs: General and Applied. 1962;76(15):1-39

9. Heggie V. Experimental physiology, Everest and oxygen: from the ghastly kitchens to the gasping lung. The British Journal for the History of Science. 2012;46(1):123-47. doi: 10.1017/s0007087412000775.

10. Heggie V. Higher and colder: The success and failure of boundaries in high altitude and Antarctic research stations. Soc Stud Sci. 2016;46(6):809-32. Epub 2016/12/28. doi: 10.1177/0306312716636249. PubMed PMID: 28025914; PubMed Central PMCID: PMCPMC5207293.

11. Zundel $M$, Kokkalis $P$. Theorizing as Engaged Practice. Organization Studies. 2010;31(9-10):1209-27. doi: 10.1177/0170840610374405.

12. van Stralen D, Mercer T. High Altitude Climbing, High Reliability, COVID-19, and the Power of Observation. Neonatology Today. 2021;16(1):68-79. doi: 10.51362/neonatology. today/20211616879.

13. van Stralen D, Mercer T. The Art of Neonatology, the Art of High Reliability as a Response to COVID-19. Neonatology Today. 2021;16(2):74-83. doi: 10.51362/neonatology. today/202121627483.

14. Arnold III AV. Strategic visioning: What it is and how it's done. Carlisle Barracks, PA: United States Army War College, 1991.

15. Magee RR. Strategic leadership primer. Carlisle Barracks, PA: United States Army War College, 1998.

16. Szakolczai A. Liminality and experience: Structuring transitory situations and transformative events. International Political Anthropology. 2009;2(1):141-72.
17. Van Stralen D, Inozu B, Byrum S. High Reliability for a Highly Unreliable World: Preparing for Code Blue through Daily Operations in Healthcare. North Charleston, SC: CreatSpace Publishing; 2017.

18. van Stralen D, McKay S, Williams GT, Mercer TA. Tactical Improvisation: After-Action/ Comprehensive Analysis of the Active Shooter Incident Response by the San Bernardino City Fire Department December 2, 2015. San Bernardino, CA: San Bernardino County Fire Protection District; 2018.

19. Sean M, James J, Greg S, Dominick B, Bryan H, Ditzel R, et al. Refining Operational Vertical Mobility. Journal of High Threat \& Austere Medicine. 2021:19. doi: 10.33553/jhtam.v3i1.33.

20. Fitzpatrick JS. Adapting to danger: A participant observation study of an underground mine. Sociology of Work and Occupations. 1980;7(2):131-58.

21. Hicks AM. Learning to Watch Out. Journal of Contemporary Ethnography. 2012;41(6):636-67. doi: 10.1177/0891241612452139.

22. Hastings DW, Wright DG, Glueck BC. Psychiatric Experiences of the Eighth Air Force: First Year of Combat (July 4, 1942-July 4, 1943). New York, NY The Josiah Macy, Jr. Foundation; 1944.

23. Fitzpatrick JS. Underground mining: a case study of an occupational subculture of danger [Dissertation]. Columbus, $\mathrm{OH}$ : The Ohio State University; 1974.

24. Haas J. A study of high steel ironworkers' reactions to fear and danger. Sociology of work and occupations. 1977;4(2):147-70.

25. Wright DG. Preparation for Emotional Stresses of Combat. The Air Surgeon's Bulletin. 1944:6-7.

26. Weil-Malherbe $H$, Axelrod J, Tomchick $R$. Blood-brain barrier for adrenaline. Science. 1959;129(3357):1226-7. Epub 1959/05/01. doi: 10.1126/science.129.3357.1226. PubMed PMID: 13658949.

27. Hediger H. Wild Animals in Captivity. London, UK: Butterworths Scientific Publications; 1950.

28. Sapolsky RM. Why zebras don't get ulcers: The acclaimed guide to stress, stress-related diseases, and coping. New York, NY: Holt Paperbacks; 2004.

29. Clinchy M, Sheriff MJ, Zanette LY. Predator-induced stress and the ecology of fear. Functional Ecology. 2013;27(1):56-65.

30. Kolditz TA. Research in In Extremis Settings. Armed Forces \& Society. 2016;32(4):655-8. doi: 10.1177/0095327x05283853.

31. Weick KE. Organizing for Transient Reliability: The Production of Dynamic Non-Events. Journal of Contingencies and Crisis Management. 2011;19(1):21-7. doi: 10.1111/j.14685973.2010.00627.x.

32. Haas J. Binging: Educational control among high steel ironworkers. American Behavioral Scientist. 1972;16(1):27-34.

33. Tempest S, Starkey K, Ennew C. In the Death Zone: A study of limits in the 1996 Mount Everest disaster. Human Relations. 2016;60(7):1039-64. doi: 10.1177/0018726707081157.

34. Elmes $M$, Frame $B$. Into hot air: $A$ critical perspective on Everest. Human Relations. 2008;61(2):213-41. doi: 10.1177/0018726707087785.

35. Pauly D. Anecdotes and the shifting baseline syndrome of fisheries. Trends in Ecology \& Evolution. 1995;10(10):430.

36. Vaught $C$, Wiehagen WJ. Escape from a Mine Fire: Emergent Perspective and Work Group Behavior. The Journal of Applied Behavioral Science. 2016;27(4):452-74. doi: 10.1177/0021886391274006.

37. Bandura A. Social learning theory. Hoboken: NJ: PrenticeHall; 1977.

38. Becker MD. "We Make Marines:" Organizational Socialization and the Effects of" The Crucible" on the Values Orientation of Recruits During US Marine Corps Training [Dissertation]. Indiana, PA: Indiana University of Pennsylvania; 2013.

39. Novaco RW, Cook TM, Sarason IG. Military Recruit Training: 
An Arena for Stress Coping Skills. In: Meichenbaum D, Jaremko ME, editors. Stress Reduction and Prevention. New York, NY: Plenum Press; 1989. p. 377-418.

40. Novaco RW, Sarason IG, Robinson GL, Parry C. Attributes of Drill Instructor School Graduates: Stress-Related Factors. Arlington, VA: Office of Naval Research, 1983 DI-ONR-001.

41. Sarason IG, Novaco RW. Stress and Coping in Recruit Training: Roles of the Recruit and the Drill Instructor. Arlington, VA: OFFICE OF NAVAL RESEARCH, 1982 AR-ONR-008.

42. Cook TM, Novaco RW, Sarason IG. Generalized Expectancies, Life Experiences, and Adaptation to Marine Corps Recruit Training. Arlington, VA: Office of Naval Research, 1980 Contract No.: AR-002.

43. Novaco RW, Sarason IG, Cook TM, Robinson GL, Cunningham FJ. Psychological and Organizational Factors Related to Attrition and Performance in Marine Corps Recruit Training. Arlington, VA: Office of Naval Research, 1979 AR-001.

44. Tatar M. Off with their heads!: Fairy tales and the culture of childhood. Princeton, NJ: Princeton University Press; 1992.

45. van Stralen D, Mercer T. Pandemic COVID-19, the High-Reliability Organization (HRO), and the Ecology of Fear. Neonatology Today. 2020;15(12):129-38. doi: 10.51362/neonatology.today/2020121512129138.

46. Cozolino L. The Neuroscience of Human Relationships: Attachment and the Developing Social Brain. New York, NY: W. W. Norton; 2006.

47. Macdonald K, Macdonald TM. The peptide that binds: a systematic review of oxytocin and its prosocial effects in humans. Harv Rev Psychiatry. 2010;18(1):1-21. Epub 2010/01/06. doi: 10.3109/10673220903523615. PubMed PMID: 20047458.

48. Bartz JA, Zaki J, Bolger N, Ochsner KN. Social effects of oxytocin in humans: context and person matter. Trends Cogn Sci. 2011;15(7):301-9. Epub 2011/06/24. doi: 10.1016/j. tics. 2011.05.002. PubMed PMID: 21696997.

49. Kirsch P, Esslinger C, Chen Q, Mier D, Lis S, Siddhanti S, et al. Oxytocin modulates neural circuitry for social cognition and fear in humans. J Neurosci. 2005;25(49):11489-93. Epub 2005/12/13. doi: 10.1523/JNEUROSCI.3984-05.2005. PubMed PMID: 16339042; PubMed Central PMCID: PMCPMC6725903.

50. Kerber B, Dreckshage BJ. Lean Supply Chain Management Essentials: A Framework for Materials Managers. Boca Raton, FL: CRC Press; 2011.

51. MacDuffie JP, Helper S. Creating Lean Suppliers: Diffusing Lean Production through the Supply Chain. California Management Review. 1997;39(4):118-51.

52. Eggers JT, Porter RI, Gray. JW. Leading and Managing Those Working and Living in Captive Environments. In: Sweene P, Matthew MD, Lester PB, editors. Leadership in Dangerous Situations: A Handbook for the Armed Forces, Emergency Services, and First Responders. Annapolis, MD: Naval Institute Press; 2011. p. 273-90.

53. Rochlin GI, Porte TRL, Roberts KH. The Self-Designing High-Reliability Organization: Aircraft Carrier Flight Operations at Se. Naval War College Review. 1987;40(4):76-92.

54. Roberts $\mathrm{KH}$, Bea R. Must accidents happen? Lessons from high-reliability organizations. Academy of Management Perspectives. 2001;15(3):70-8. doi: 10.5465/ ame.2001.5229613.

Disclosure The authors have no disclosures.

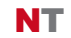

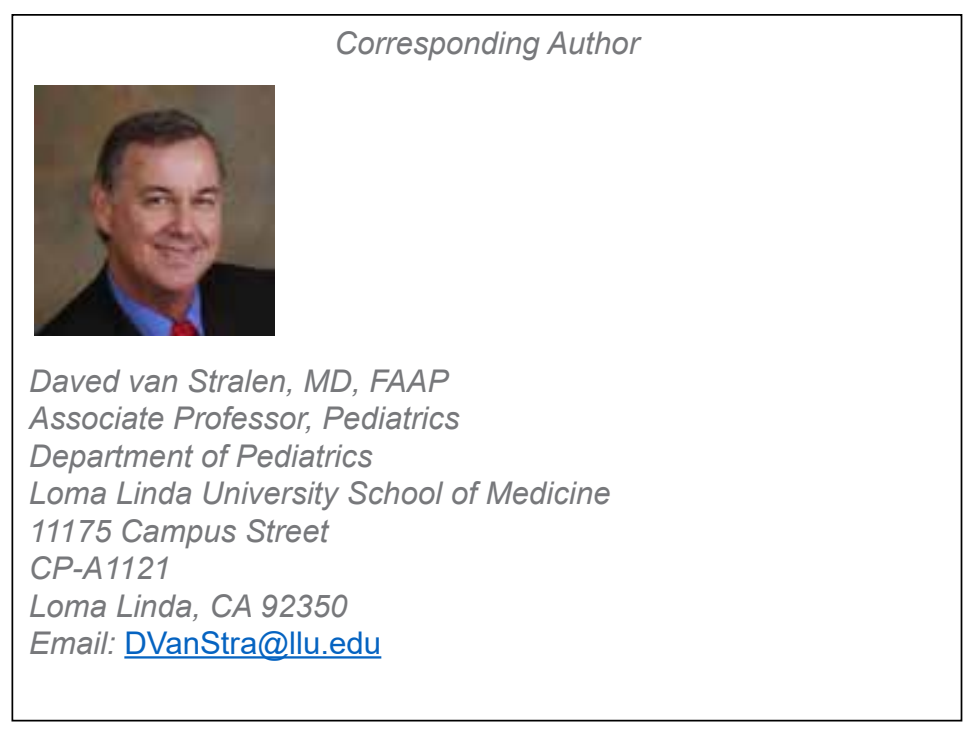

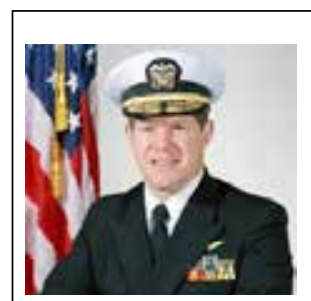

Thomas A. Mercer

Rear Admiral

United States Navy (Retired)

\section{Acknowledgments}

Karl Weick, Rensis Likert Distinguished University Professor of Organizational Behavior and Psychology, Emeritus, University of Michigan

William J. Corr, formerly with the Los Angeles City Fire Department, now deceased

Raymond Novaco, Professor, Psychology and Social Behavior, School of Social Ecology, University of California, Irvine, California

Sean McKay, Element Rescue, LLC

Errol van Stralen, Ancora Education

William Gambino, CIV, DoD

Readers can also follow NEONATOLOGY via our Twitter Feed @NEOTO 